\title{
Evaluating the Credibility of the European Bank Bail-In Commitment
}

\author{
Paul C. Noller $^{1}$ (D)
}

Published online: 4 January 2019

(C) The Author(s) 2019

JEL $\mathrm{F} 30 \cdot \mathrm{G} 10 \cdot \mathrm{G} 15 \cdot \mathrm{G} 20 \cdot \mathrm{L} 50$

When Jonathan Hill, the former European Union (EU) Commissioner for Financial Services, introduced the Bank Recovery and Resolution Directive (BRRD) to the people of Europe, he made an eminent promise: "From now on, it will be the banks' shareholders and their creditors who will bear the related costs and losses of a failure rather than the taxpayer" (European Commission, A single rulebook for the resolution of failing banks will apply in the EU as of 1 January 2015, 2014). In order to keep that promise, the BRRD suggested that debt corresponding to at least $8 \%$ of total liabilities should be written off before a failing bank should be recapitalized with public money.

This promise entailed a delicate balancing act of maintaining financial stability whilst avoiding unduly subsidising systemically important banks (SIBs). This balance rested on investors expecting the bail-in and the market reflecting the risk of default in the yield of senior SIB bonds. If they did not, an unanticipated bail-in during a financial crisis could spark an overreactive price correction on bond yields culminating in a liquidity freeze and collapse of the interbank market. Thus, any doubts about the European Central Bank's (ECB) commitment to carry through on the bail-in could have become a self-enforcing, self-fulfilling prophecy, where even regulators with every intention of delivering cannot risk the implications of surprising markets.

This research conceptualized and quantified the EU's credibility regarding bail-in as the expected loss-absorption on assets before bailout (ELAB), or, simply put, the expected value of losses imposed on bond-holders of a failing bank as a percentage of its total assets. The constituent models were all estimated for the period from 05/02/ 2017 to 02/16/2018, with separate estimates for pre-, post- and within June 2017. In that month, two bailouts took place in Italy. Invoking article 32(b) of the BRRD, the

Paul C. Noller

p.c.noller@outlook.com

1 Department of Economics, University of Warwick, Coventry, UK 
ECB waved the $8 \%$ requirement leading up to a bailout by the Italian treasury. June also saw the first application of the BRRD with a shallow bail-in of Banco Popular. This period was crucial for the formation of market expectations.

ELAB was obtained by first calculating the yearly expected value of bank bailouts (implicit subsidy) to SIBs. Using credit default swap (CDS) spreads, the random effects regression isolated the yield spread between the senior bonds of SIBs and less significant banks (LSBs) unaccounted for by equity-derived default risk variables of the sampled banks. The statistically significant funding advantage thusly obtained was scaled by cumulative short-term debt to derive the implicit subsidy. This calculation, which was unprecedented for the Eurozone, placed the yearly wealth transfer from EU treasuries to banks at between $€ 7.9$ billion for the main model and $€ 16.3$ billion for the control model over the whole estimation period. The main model also found a $€ 5$ billion increase took place as risk and credibility shifted following the events of June.

A failure to sufficiently isolate shifts in credibility from those in risk was a major shortcoming of previous papers on the topic. To achieve this isolation, a Black-Scholes model was used, supposing a one-year, European put option on systemic assets held by the banking system against the government. Substituting the implicit subsidy for the price of the option and using implied volatility to project market expectations of future systemic asset volatility, ELAB was deduced as a transformation of the strike price on the option. The results showed ELAB fell from $7.55 \%$ to $6.73 \%$ pre- to post-June, with the control model yielding an even lower average value of $6.04 \%$ overall. The $6.73 \%$ ELAB value fell short of the bail-in scenario set out in the BRRD, demonstrating that markets, on average, do not expect a deep write-off of senior bonds.

The result showed that regulators, particularly the ECB, which has the last word in waving the BRRD requirements, suffer from a worrying lack of market credibility. If a financial crisis were to occur within the existing framework, the EU could be forced to choose between backtracking on Commissioner Hill's promise or once again risking widespread financial distress across the Eurozone triggered by a liquidity crisis and the subsequent credit freeze.

The paper contributed two-fold: First, the conceptualization of ELAB created a tool allowing for a quantitative comparison of bail-in credibility on an intuitive scale, which facilitates the prediction of a precise, average loss-allocation scenario in resolution given any bank's particular capital structure. This could prove highly useful for markets in providing certainty and for regulators by allowing them to adequately manage and monitor their credibility standing with markets. This result in particular could also have a profound impact on the rationale behind designing prudential regulation by reaffirming moral hazard as a part of the political equation. A supplementary contribution was the calculation of an implicit subsidy for the eurozone, quantifying support to the banks and illustrating the yearly wealth transfer from society to banks. Limitations lie in the necessity to use fairvalue CDS spreads to approximate certain LSB CDS spreads, imposing an assumption of market efficiency, and the somewhat limited time span of the event study.

Open Access This article is distributed under the terms of the Creative Commons Attribution 4.0 International License (http://creativecommons.org/licenses/by/4.0/), which permits unrestricted use, distribution, and reproduction in any medium, provided you give appropriate credit to the original author(s) and the source, provide a link to the Creative Commons license, and indicate if changes were made.

Publisher's Note Springer Nature remains neutral with regard to jurisdictional claims in published maps and institutional affiliations. 